\title{
Clinicians' Attitude Toward Computer-Guided Implant Surgery Approach: Survey in Saudi Arabia
}

This article was published in the following Dove Press journal:

Pragmatic and Observational Research

\author{
Linah M Ashy \\ Department of Oral and Maxillofacial \\ Prosthodontics, King Abdulaziz \\ University Faculty of Dentistry (KAUFD), \\ Jeddah, Saudi Arabia
}

Purpose: To investigate the attitude of clinicians in Saudi Arabia towards dental implant treatment using different implant surgery approaches.

Materials and Methods: This cross-sectional observational study was conducted using a web-based questionnaire wherein 56 clinicians ranked their attitude toward computerguided implant surgery (CGIS) and conventional non-computer-guided surgery (non-CGIS) in terms of advantages, disadvantages and clinical indications. Statistical analysis was conducted by the Spearman correlation test, Kruskal-Wallis test, and Wilcoxon rank sum tests, at a significance level of $P<0.05$.

Results: The survey results indicated that the most significant advantages of CGIS from the participants' perspective were low levels of stress during surgery $(P=0.003)$ and minimal requirement of surgical skills $(P=0.04)$. Notably, the advantages of accurate outcome and predictable flapless surgery were not considered significantly higher for CGIS than for nonCGIS ( $P=0.2$ and 0.7 , respectively). The high treatment cost was the most significant disadvantage of CGIS when compared to non-CGIS $(P=0.002)$, and complete edentulism was the most recommended clinical condition for CGIS.

Conclusion: Clinicians acknowledged the advantages of CGIS over non-CGIS, especially in complete edentulism. The significant advantages of CGIS were the clinician's state of low stress and minimal skills required rather than the patient's interest in treatment predictability. CGIS is an attractive approach for most participants, in spite of the low rate of actual use.

Keywords: clinician-based outcome, dental implant, guided placement

\section{Introduction}

Following the introduction of virtual dental implant planning in 1999, computerguided implant surgery (CGIS) has been one of the most evolving areas in digital dentistry. Principally, it involves computed tomography (CT) of the jaw, imaging of the planned prosthesis, placement of a virtual implant, and production of a stereolithographic surgical guide for the actual placement of the implant. This technology facilitates surgical execution of implant placement based on ideal prosthetic positioning and radiographic anatomic considerations. ${ }^{1}$ When introduced, advantages anticipated were increased accuracy of implant position, reduced surgery invasiveness, shortened chair-side time, and increased patient acceptance of dental implant treatment. ${ }^{2}$ Additionally, numerous studies have reported an implant survival rate of $91 \%$ to $100 \%$ with CGIS. ${ }^{3-6}$ Although increased accuracy of implant position has been reported, ${ }^{6,7}$ some studies revealed a considerable threedimensional (3-D) deviation between virtual planning and the actual implant position. ${ }^{8,9}$ To improve the outcome of the implant position, several factors have
Correspondence: Linah M Ashy

Prosthodontics, King Abdulaziz University

Faculty of Dentistry, P.O.Box 80209 ,

Jeddah, 21589, Saudi Arabia

Tel +96650567999l

Email lashy@kau.edu.sa
Pragmatic and Observational Research 2021:12 I-8

(c) (1) () 202I Ashy. This work is published and licensed by Dove Medical Press Limited. The full terms of this license are available at https://www.dovepress.com/terms.php and (1) incorporate the Creative Commons Attribution - Non Commercial (unported, v3.0) License (http://creativecommons.org/licenses/by-nc/3.0/). By accessing the work you hereby accept the Terms. Non-commercial uses of the work are permitted without any further permission from Dove Medical Press Limited, provided the work is properly attributed. For permission for commercial use of this work, please see paragraphs 4.2 and 5 of our Terms (https://www.dovepress.com/terms.php). 
to be considered, including quality of CT imaging, the clinician's knowledge of CT analysis, quality of 3-D reconstruction, ${ }^{10}$ and precise transfer of the virtual plan to the intraoral position using fixed intraoral reference points. ${ }^{11-13}$ The computer-guided approach could be the less preferred one by the clinician or the patient for numerous reasons: the additional cost, elongated treatment planning time, and learning curve associated with the application of this technology. Nowadays, software designers and 3-D printing manufacturers have rapidly encompassed implant dentistry into the digital industry. Therefore, it is essential that dental caregivers evaluate the necessity of incorporating the digital dentistry approach into their patient care routine. The aim of this study was to investigate and compare the attitude of clinicians toward computer-guided implant surgery (CGIS) and conventional non-CGIS in dental implant treatment.

\section{Materials and Methods}

This observational cross-sectional study was approved by the Research Ethics Committee of the Faculty of Dentistry (REC-FD) at King Abdulaziz University (Ethical approval \# 42-38828) in full accordance with the World Medical Association Declaration of Helsinki. Verbal informed consent process was approved by the REC-FD and obtained from all participants. The current methodology was reviewed by an independent statistician.

A web-based questionnaire was prepared using the Survey Monkey website (Survey Monkey, San Mateo, CA, USA). The development of the survey was based on the reported advantages, disadvantages, and criteria for CGIS and the conventional approach in the literature complemented by the author's opinion. Questionnaire items were reviewed by two dentists familiar with digital implant dentistry for clarity of instructions and questions, order of questions, and comprehensiveness. Following the review, an agreement on the items to be included in the questionnaire was reached.

A pilot survey was undertaken by 20 dentists to test the lucidity of the questions. The questionnaire was then modified before proceeding with the actual study. Reliability analysis performed on the data collected from 20 participants using IBM Statistical Package for the Social Sciences (SPSS version 22 software; Armonk, NY, USA) reported Cronbach's alpha of $0.72,0.73$, and 0.83 .

From October 2017 to February 2018, the questionnaire was electronically sent to 150 dental professionals who had the experience of placing 10 or more dental implants. The targeted subjects included faculty members and Saudi board residents in the implantology, oral surgery, periodontics, and prosthodontics disciplines at King Abdulaziz University (Jeddah, Saudi Arabia) and King Saud University (Riyadh, Saudi Arabia), as well as members of the Saudi Implant Club. This cohort represented the dentists practicing implantology in Saudi Arabia.

The questionnaire was in English and included 30 questions distributed over 3 pages. The first page involved questions on gender, specialty (general dentists, periodontists, oral surgeons, prosthodontists), experience with implant placement in terms of number of implants placed (placed $<100$ implants, placed 100-200 implants, or placed $>200$ implants), experience with using CGIS (users or nonusers), and interest in using this technology (interested or not-interested). The second page had statements on parameters related to non-CGIS procedures, including implant position accuracy, chair-side time, predictability of flapless surgery, keeping pace with technological developments, surgery-related stress, required surgical skills, treatment cost, and treatment planning time. Finally, the last page included the same statements, but in relation to CGIS, along with parameters specific to CGIS, such as accessibility to training courses, access to planning software, learning curve, communication with production centers, and different clinical situations where CGIS is indicated. On a 10point Likert scale, participants were expected to choose a number from 0 (totally disagree) to 10 (totally agree) for each given statement. The list of included questions are shown in Table 1. Data entry was carried out manually, and statistical analysis was conducted using STATA Version 13.0 (StataCorp, College Station, Texas, USA). Descriptive analysis variables were presented using frequencies and percentages (gender, specialty, experience level, using status, and interest). The outcome variables of the participants' attitude toward the characteristics of guided and non-guided surgery were presented using median and interquartile range, and the association between them was tested using the Spearman correlation test. Furthermore, the association between outcome variable (attitude toward characteristics of guided surgery) and predictors (gender, specialty, experience level, actual use) was tested using Kruskal-Wallis and Wilcoxon rank sum tests, with $P<0.05$ indicating significance.

\section{Results}

The results were reviewed by an independent statistician. This study included responses from 56 clinicians, 
Table I The Study Questionnaire

\section{Clinician's Attitude Towards Computer-Guided Implant Surgery Approach Questionnaire}

I. What is your gender?

- Male

- Female

2. What is your specialty?

- General dentistry

- Oral surgery

- Periodontics

- Prosthodontics

3. How many implants have you placed?

- 10-100

- 100-200

- More than 200

4. Have you ever placed an implant using a computer-guided surgical stent?

- Yes

- No

5. Are you interested in computer-guided implant surgery?

- Yes

- No

Regarding non computer-guided implant surgery and on an ascending scale of ten, choose a number (totally disagree 0-1-2-3-4-5-6-7-8-9-10 totally agree) that appropriately represent your agreement on the following statements.

6. With non-guided surgery, implant position outcome is highly accurate.

7. With non-guided surgery, chair-side time is short.

8. With non-guided surgery, flapless surgery is predictable

9. Non-guided surgery, adequately, keeps pace with technology.

10. With non-guided surgery, clinician's intraoperative stress is low.

II. With non-guided surgery, clinician's surgical skills is not critical.

12. With non-guided surgery, treatment cost is high.

13. With non-guided surgery, treatment planning time is lengthy.

Regarding computer-guided implant surgery and on an ascending scale of ten, choose a number (totally disagree 0-1-2-3-4-5-6-7-8-9-10 totally agree) that appropriately represent your agreement on the following statements.

14. With guided surgery, implant position outcome is highly accurate.

15. With guided surgery, chair-side time is short.

16. With guided surgery, flapless surgery is predictable

17. Guided surgery, adequately, keeps pace with technology.

18. With guided surgery, clinician's intraoperative stress is low.

19. With guided surgery, clinician's surgical skills is not critical.

20. With guided surgery, treatment cost is high.

21 . With guided surgery, treatment planning time is lengthy.

22. For guided surgery, training courses are inaccessible.

23. For guided surgery, planning software is inaccessible.

24. For guided surgery, learning curve is steep.

25. For guided surgery, communication with production centers is inconvenient.

26. Guided surgery is indicated in single anterior edentulous gap situations.

27. Guided surgery is indicated in single posterior edentulous gap situations.

28. Guided surgery is indicated in extended anterior edentulous gap situations.

29. Guided surgery is indicated in extended posterior edentulous gap situations.

30. Guided surgery is indicated in completely edentulous situations. 
a response rate of $37.3 \%$. Baseline characteristics of participants are presented in Table 2. Although 95\% of participating clinicians were interested in applying CGIS, only $46 \%$ of them had used the technology. Participants in the current investigation had the following attitude toward CGIS:

1. Clinicians acknowledged the advantages of CGIS over non-CGIS (Figure 1).

2. The most significant advantages of CGIS over nonCGIS were low stress during surgery $(P=0.003$, Spearman correlation) and the reduced level of required surgical skills ( $P=0.04$, Spearman correlation) (Figure 1).

3. The advantages of a more accurate outcome and a more predictable flapless surgery were not significantly higher with CGIS than with non-CGIS $(P=$ 0.2 and 0.7 , respectively, Spearman correlation) (Figure 1).

4. The most significant disadvantage of CGIS over non-CGIS was the increased cost of treatment $(P=$ 0.002, Spearman correlation) (Figure 1).

5. Clinicians rated accessibility to CGIS as moderate (Figure 2).

6. The acknowledgement of the advantages of predictable flapless surgery in association with CGIS was significantly higher among general dentists than among periodontists and prosthodontists $(P=0.03$, Kruskal-Wallis test) (Figure 3).
Table 2 Number and Percentage of Participants According to Gender, Specialty, Experience Level with Implant Placement in Terms of Quantity, Experience with the Use of ComputerGuided Implant Surgery (CGIS), and Interest in Using CGIS

\begin{tabular}{|l|l|l|}
\hline $\begin{array}{l}\text { Baseline } \\
\text { Characteristics of } \\
\text { Participants }\end{array}$ & $\begin{array}{l}\text { Number of } \\
\text { Participants } \\
\text { (n=56) }\end{array}$ & $\begin{array}{l}\text { Percentage of } \\
\text { Participants }\end{array}$ \\
\hline $\begin{array}{l}\text { Gender } \\
\text { Male }\end{array}$ & 37 & 66 \\
Female & 19 & 34 \\
\hline $\begin{array}{l}\text { Specialty } \\
\text { General dentists }\end{array}$ & 4 & \\
Oral surgeons & 7 & 7 \\
Periodontists & 20 & 12 \\
Prosthodontists & 25 & 36 \\
\hline $\begin{array}{l}\text { Experience level (Number } \\
\text { of placed implants) }\end{array}$ & & 45 \\
I0-I00 implant & 14 & \\
I00-200 implant & 14 & 25 \\
$>200$ implant & 28 & 25 \\
\hline Use of CGIS & & 50 \\
Yes & 26 & 55 \\
No & 30 & 54 \\
\hline Interest in CGIS & 53 & \\
Yes & 3 & \\
No & & \\
\hline
\end{tabular}

7. Neither their level of experience nor the frequency with which they used the technology significantly influenced the participants' opinion about CGIS (Figures 4 and 5).

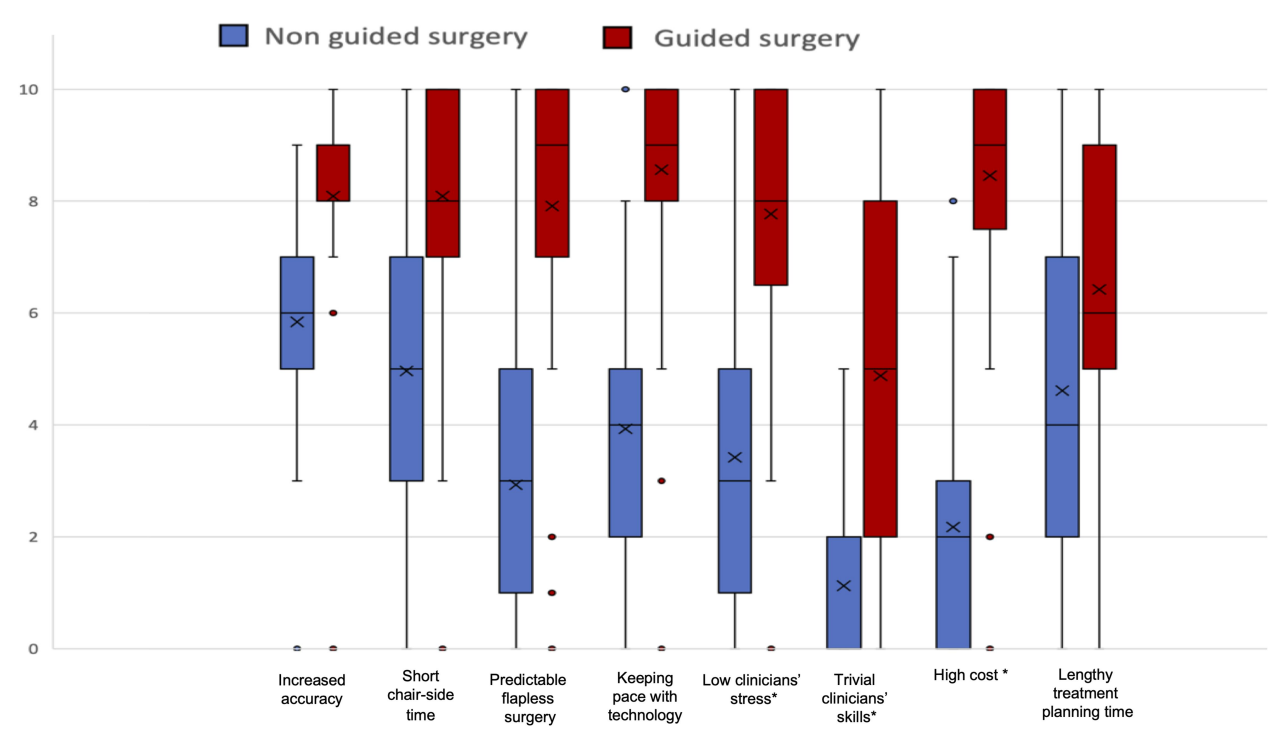

Figure I Median and interquartile range of the attitude of clinicians toward the advantages and disadvantages of computer-guided implant surgery (CGIS) versus the conventional non-CGIS approach on a scale of 0 (totally disagree) to 10 (totally agree). *Statistically significant difference at $P<0.05$. 


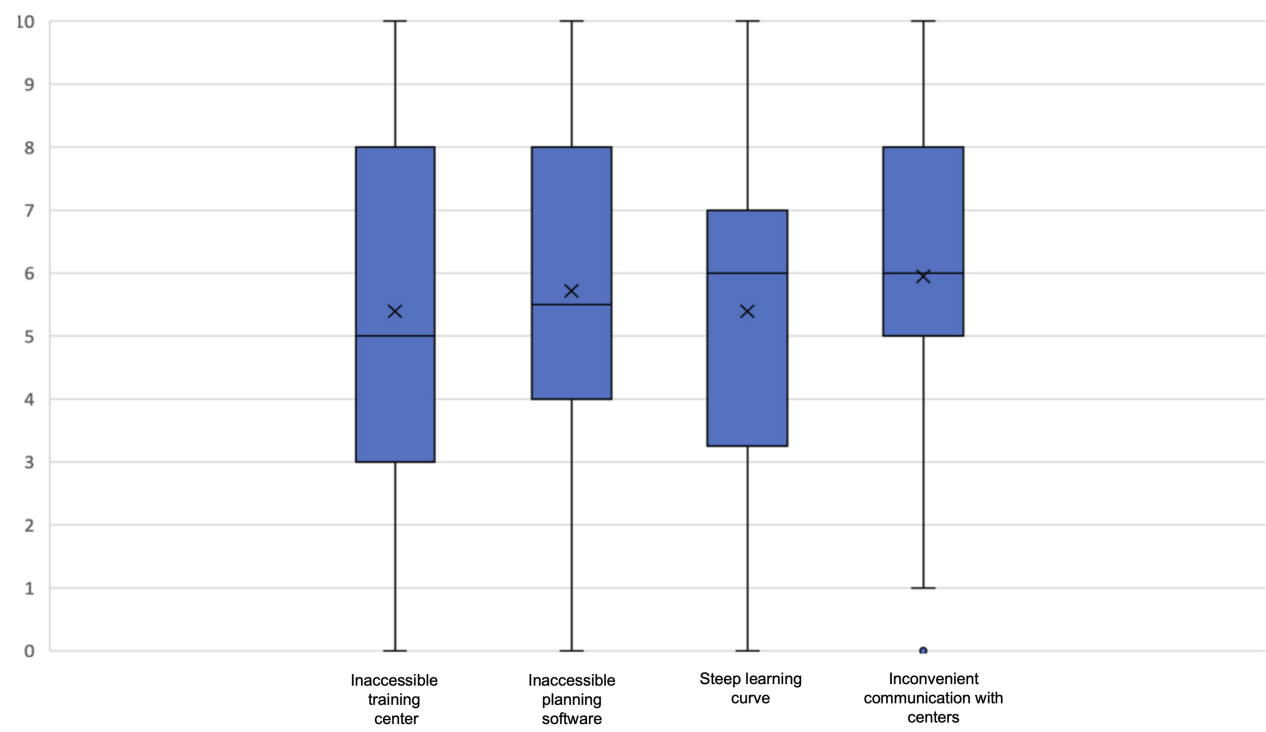

Figure 2 Median and interquartile range of the attitude of clinicians toward disadvantages specific to computer-guided implant surgery (CGIS) on a scale of 0 (totally disagree) to 10 (totally agree).

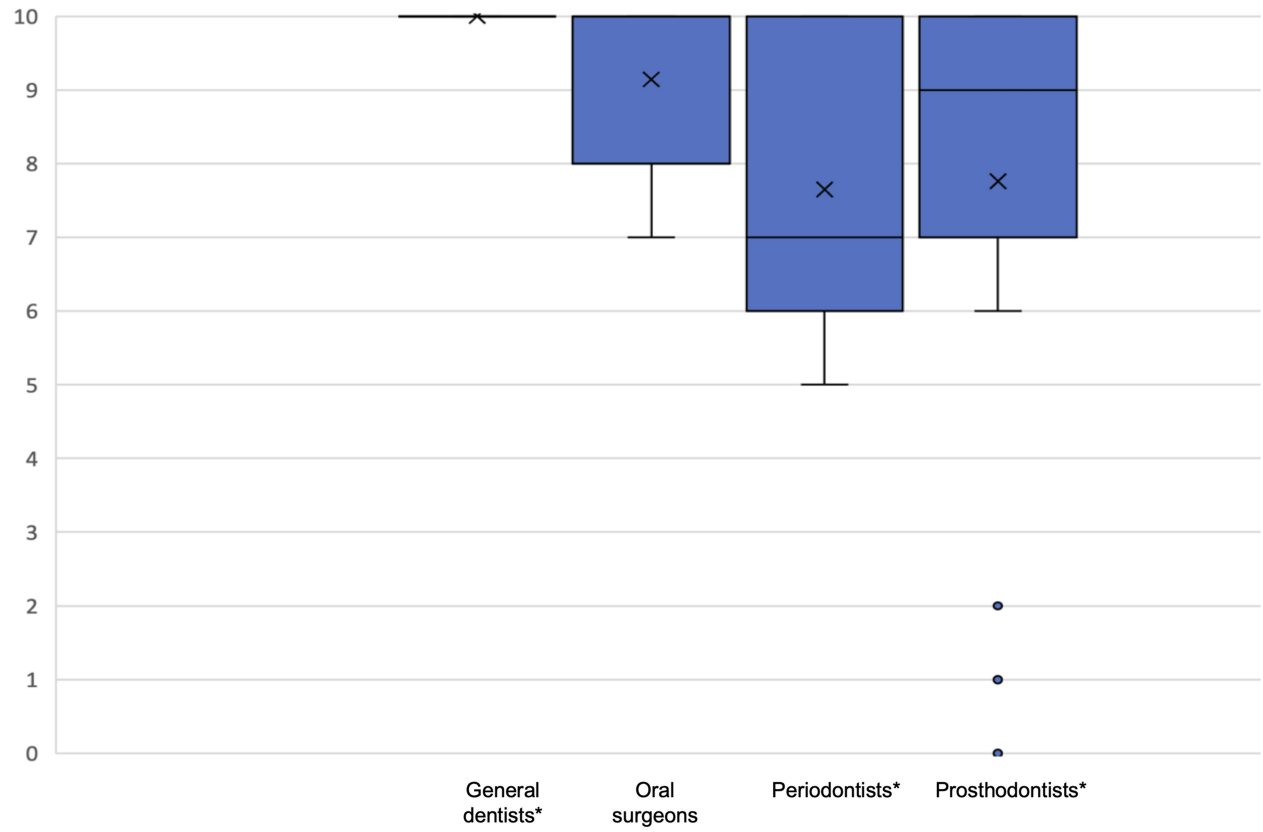

Figure 3 Median and interquartile range of the attitude of clinicians from different specialties towards the predictability of flapless implant surgery with computer-guided implant surgery (CGIS) on a scale of 0 (totally disagree) to 10 (totally agree). *Statistically significant difference at $P<0.05$.

8. CGIS was the most recommended in cases of complete edentulism and the least recommended in treating single posterior edentulous gaps.

\section{Discussion}

The general observation of this study was that the participants acknowledged the advantages of CGIS over the conventional approach. Specifically, they believed that CGIS was associated with significantly lower stress among clinicians and a reduced level of required surgical skills. However, they did not consider the accuracy of the outcome and the predictability of flapless surgery as significant advantages of CGIS. Therefore, the main advantages of CGIS, as seen by the participants, were related to the clinician's state of low stress rather than the patient's interest in treatment predictability.

In contrast to what participants considered regarding accuracy outcome in the current study, few studies in 


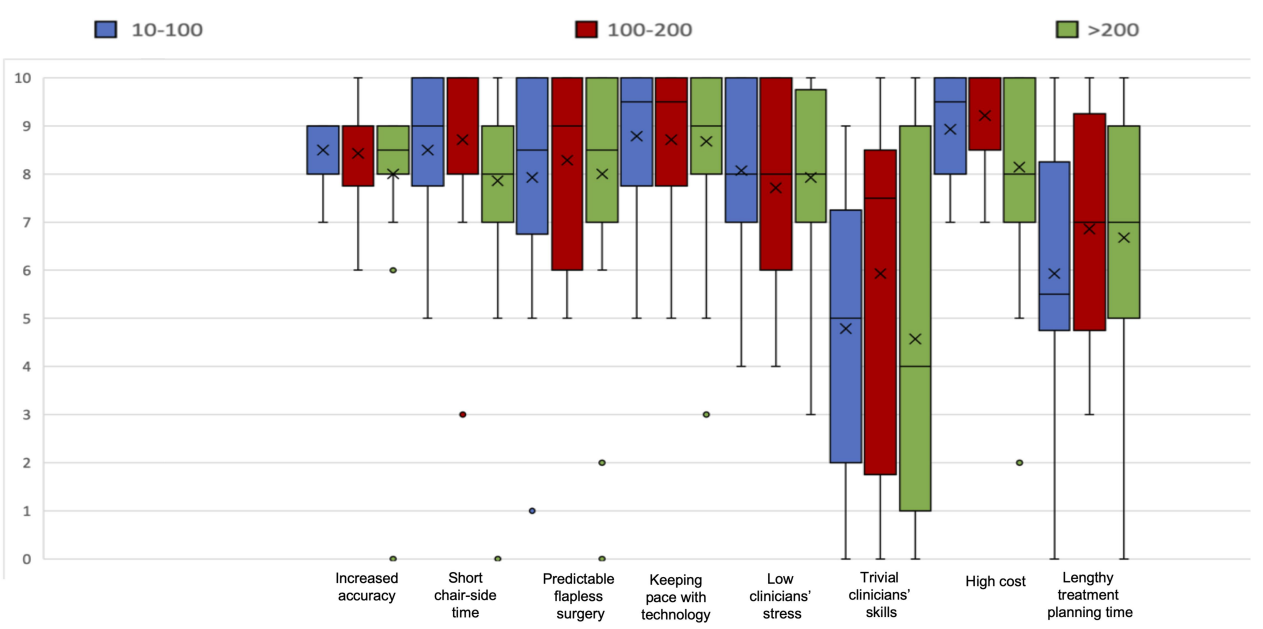

Figure 4 Median and interquartile range of the attitude of clinicians with different levels of experience toward the advantages and disadvantages of computer-guided implant surgery (CGIS) on a scale of 0 (totally disagree) to 10 (totally agree).

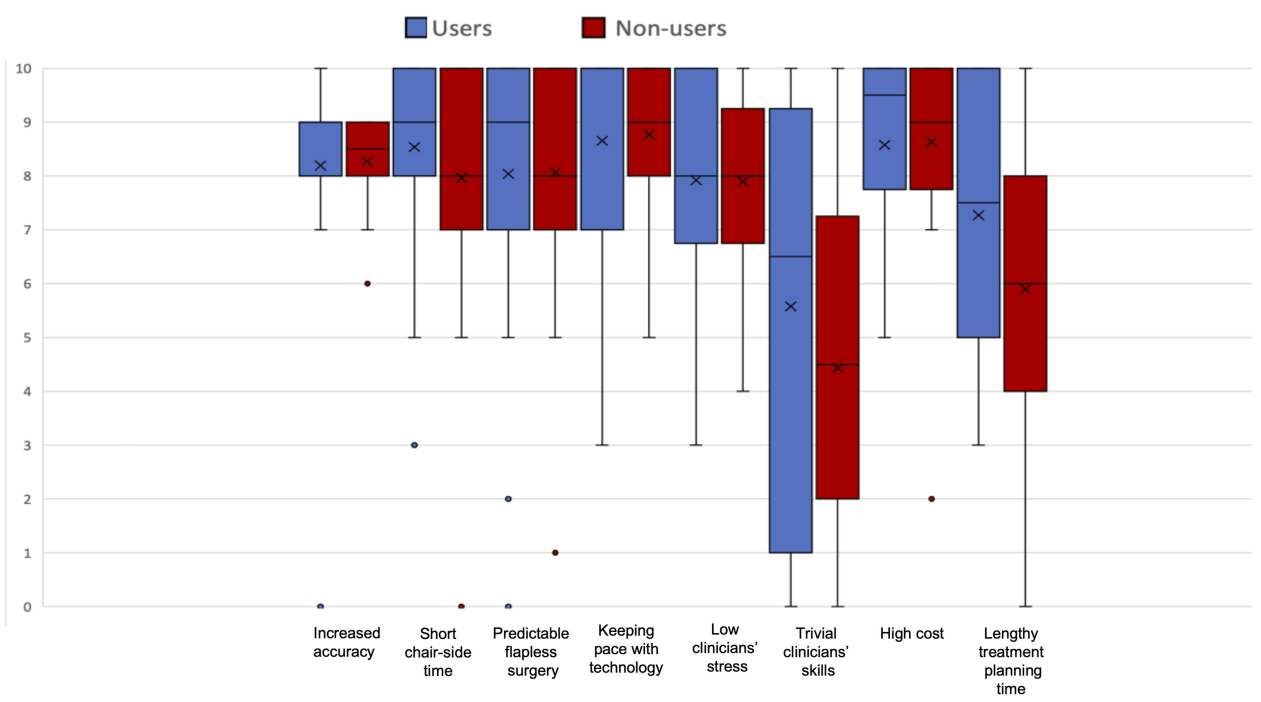

Figure 5 Median and interquartile range of the attitude of computer-guided implant surgery (CGIS) users and non-users toward the advantages and disadvantages of computer-guided implant surgery (CGIS) on a scale of 0 (totally disagree) to 10 (totally agree).

the literature have reported that the accuracy of CGIS was significantly more than that of the non-guided surgery. In a recent study comparing the accuracy of implant placement between a thermoplastic surgical guide and 3-D printed surgical guide, a significant difference was found in the location of implant head position $(1.3 \mathrm{~mm}$ and $0.51 \mathrm{~mm}$, respectively) and implant apex position $(1.60 \mathrm{~mm}$ and $0.76 \mathrm{~mm}$, respectively), but not in the implant angulation (3.40 degrees and 2.36 degrees, respectively). The difference in the accuracy outcome due to the greater flexibility of the thermoplastic surgical guide, leading to increased probability of faulty position outcome. ${ }^{14}$ Another study evaluating the difference between the accuracy result of computer- guided surgery and free-hand surgery performed by experienced dentists demonstrated a 3-times greater deviation in the final position of placed implants at the angular level and significant deviation at the lateral levels associated with the free-hand approach. ${ }^{15}$ However, this increased accuracy outcome may not be adequate in all situations, because $\pm 2 \mathrm{~mm}$ imprecisions in association with guided surgery are to be expected. ${ }^{12}$

The predictability of flapless surgery using CGIS was acknowledged by the general dentists in this study. A previous study demonstrated that flapless placement of implants without utilizing a surgical guide is an inaccurate procedure that may result in bone perforation in $59.7 \%$ of the cases. ${ }^{16}$ 
Although $95 \%$ of the study participants were interested in using CGIS, only $46 \%$ reported using the technology. The retraction from CGIS could be related to few factors. First, the high cost of CGIS was the major disadvantage reported here. However, a report on the patient's perception on dental implant surgery showed that $67 \%$ of patients would accept the expenses of guided surgery if it precludes a bone grafting procedure. ${ }^{17}$ Second, participants in this study reported poor accessibility to training courses on CGIS, planning software, or communication with surgical guide production centers. These factors are speculated to hinder the utilization of this technology.

In this study, the clinicians mostly recommended the use of CGIS in complete edentulous cases. Issues regarding ideal positioning of multiple implants in relation to the final restoration to each other and to the surrounding anatomical structures can be dealt with when using the computer-guided approach. ${ }^{18,19}$ However, in a systematic review evaluating the guided surgery approach in the treatment of fully edentulous patients, complications such as surgical guide fracture, reduced primary implant stability, and prosthesis fracture were seen in spite of the high survival rate of $97.2 \%$, with a mean marginal bone loss of $1.45 \mathrm{~mm}$ over a follow-up period of $1-4$ years. $^{20}$

Shortcomings of the current survey included the small sample size and the selection of a convenient sample that makes external generalization of the results beyond the targeted population difficult. Therefore, this survey represents the attitude of dentists practicing implantology in Saudi Arabia. Results may vary in other countries where the market size of digital implant dentistry, available resources, and level of experience with the technology are different.

\section{Conclusion}

Within the limitations of the current investigation, the following can be concluded in the present study:

- Clinicians acknowledged the advantages of CGIS over non-CGIS.

- The significant advantages of CGIS were related to the clinician's state of low stress and reduced level of required skills, rather than the patient's interest in treatment predictability.

- CGIS is an attractive approach for most clinicians, in spite of the low rate of actual experience.

Future research can be directed toward investigating the attitude of patients toward CGIS, by conducting controlled clinical trials to compare the outcome of CGIS and nonCGIS in various clinical situations and to delineate clinical criteria for proper case selection.

\section{Acknowledgments}

The author would like to express her thanks to all the participants in this study, to the biostatistician Dr.Meaad Moqaddam form King Abdulaziz University Faculty of Dentistry for her valid contribution in reviewing the current work and to Editage (www.editage.com) for English language editing. No financial support was received for this investigation.

\section{Disclosure}

The author reports no conflicts of interest in this work.

\section{References}

1. D'Souza KM, Aras MA. Types of implant surgical guides in dentistry: a review. J Oral Implantol. 2012;38(5):643-652. doi:10.1563/ AAID-JOI-D-11-00018

2. Fortin T, Bosson JL, Isidori M, Blanchet E. Effect of flapless surgery on pain experienced in implant placement using an image-guided system. Int J Oral Maxillofac Implants. 2006;21:298-304.

3. Schneider D, Marquardt P, Zwahlen M, Jung RE. A systematic review on the accuracy and the clinical outcome of computer guided template-based implant dentistry. Clin Oral Implants Res. 2009; 20:73-86. doi:10.1111/j.1600-0501.2009.01788.x

4. Hultin M, Svensson KG, Trulsson M. Clinical advantages of computer guided implant placement: a systematic review. Clin Oral Implants Res. 2012;23:124-135. doi:10.1111/j.1600-0501.2012.025 45.x

5. Merli M, Bernardelli F, Esposito M. Computer-guided flapless placement of immediately loaded dental implants in the edentulous maxilla: a pilot prospective case series. Eur J Oral Implantol. 2008;1:61-69.

6. Jung RE, Schneider D, Ganeles J, et al. Computer technology applications in surgical implant dentistry: a systemic review. Int J Oral Maxillofac Implants. 2009;24:92-109.

7. Sarment DP, Sukovic P, Clinthorne N. Accuracy of implant placement with a stereolithographic surgical guide. Int J Oral Maxillofac Implants. 2003;18(4):571-577.

8. D'haese J, Van De Velde T, Komiyama A, Hultin M, De Bruyn H. Accuracy and complications using computer-designed stereolithographic surgical guides for oral rehabilitation by means of dental implants: a review of the literature. Clin Implant Dent Relat Res. 2012;14(3):321-335. doi:10.1111/j.1708-8208.2010.00275.x

9. Di Giacomo GA, Cury PR, de Araujo NS, Sendyk WR, Sendyk CL. Clinical application of stereolithographic surgical guides for implant placement: preliminary results. J Periodontol. 2005;76(4):503-507. doi:10.1902/jop.2005.76.4.503

10. Mandelaris GA, Rosenfeld AL, Nevins ML. Computer-guided implant dentistry for precise implant placement: combining specialized stereolithographically generated drilling guides and surgical implant instrumentation. Int $J$ Periodont Rest Dent. 2012;30: 275-281.

11. Holst S, Blatz MB, Eitner S. Precision for computer-guided implant placement: using 3D planning software and fixed intraoral reference points. J Oral Maxillofac Surg. 2007;65(3):393-399. doi:10.1016/j. joms.2006.10.050 
12. Vercruyssen M, Hultin M, Van Assche N, Svensson K, Naert I, Quirynen M. Guided surgery: accuracy and efficacy. Periodontol 2000. 2014;66(1):228-246. doi:10.1111/prd.12046

13. Zhou W, Liu Z, Song L, Kuo CL, Shafer DM. Clinical factors affecting the accuracy of guided implant surgery: a systematic review and meta-analysis. J Evid Based Dent Pract. 2018;18(1):28-40. doi:10.1016/j.jebdp.2017.07.007

14. Bell CK, Sahl EF, Kim YJ, Rice DD. Accuracy of implants placed with surgical guides: thermoplastic versus 3D printed. Int $J$ Periodont Rest Dent. 2018;38:113-119.

15. Vermeulen J. The accuracy of implant placement by experienced surgeons: guided vs. freehand approach in a simulated plastic model. Int $J$ Oral Maxillofac Implants. 2017;32(3):617-624. doi: $10.11607 /$ jomi.5065

16. Van de Velde T, Glor F, De Bruyn H. A model study of flapless implant placement by clinicians with a different experience level in implant surgery. Clin Oral Implants Res. 2008;19(1):66-72. doi:10.1111/j.1600-0501.2007.01423.x

17. Hof M, Tepper G, Semo B, Arnhart C, Watzek G, Pommer B. Patients' perspectives on dental implant and bone graft surgery: questionnaire-based interview survey. Clin Oral Implants Res. 2014;25(1):42-45. doi:10.1111/clr.12061
18. Van Steenberghe D, Glauser R, Blombäck U, et al. A computed tomographic scan derived customized surgical template and fixed prosthesis for flapless surgery and immediate loading of implants in fully edentulous maxillae: a prospective multicenter study. Clin Implant Dent Relat Res. 2005;7(Suppl 1):S111-S120. doi:10.1111/ j.1708-8208.2005.tb00083.x

19. Rosenfeld AL, Mandelaris GA, Tardieu PB. Prosthetically directed implant placement using computer software to ensure precise placement and predictable prosthetic outcomes; Part 3: stereolithographic drilling guides that do not require bone exposure and the immediate delivery of teeth. Int J Periodont Rest Dent. 2006;26:493-499.

20. Moraschini V, Velloso G, Luz D, Barboza EP. Implant survival rates, marginal bone level changes, and complications in full-mouth rehabilitation with flapless computer-guided surgery: a systematic review and meta-analysis. Int J Oral Maxillofac Surg. 2015;44(7):892-901. doi:10.1016/j.ijom.2015.02.013

\section{Publish your work in this journal}

Pragmatic and Observational Research is an international, peerreviewed, open access journal that publishes data from studies designed to reflect more closely medical interventions in realworld clinical practice compared with classical randomized controlled trials (RCTs). The manuscript management system is completely online and includes a very quick and fair peer-review system. Visit http://www.dovepress.com/testimonials.php to read real quotes from published authors. 